\title{
Absence of intestinal microbiota does not protect mice from diet-induced obesity
}

\author{
Christine K. Fleissner ${ }^{1} \dagger$, Nora Huebel ${ }^{2} \dagger$, Mohamed Mostafa Abd El-Bary ${ }^{2}$, Gunnar Loh $^{2}$, Susanne Klaus ${ }^{1}$ \\ and Michael Blaut ${ }^{2 *}$ \\ ${ }^{1}$ Group of Physiology of Energy Metabolism, German Institute of Human Nutrition Potsdam Rehbrücke, Arthur-Scheunert Allee \\ 114-116, 14558 Nuthetal, Germany \\ ${ }^{2}$ Department of Gastrointestinal Microbiology, German Institute of Human Nutrition Potsdam Rehbrücke, Arthur-Scheunert Allee \\ 114-116, 14558 Nuthetal, Germany
}

(Received 17 November 2009 - Revised 22 February 2010 - Accepted 15 March 2010 - First published online 5 May 2010)

\begin{abstract}
The gut microbiota has been implicated in host nutrient absorption and energy homeostasis. We studied the influence of different diets on body composition in germ-free (GF) and conventional (CV) mice. GF and CV male adult C3H mice were fed ad libitum a semi-synthetic low-fat diet (LFD; carbohydrate-protein-fat ratio: 41:42:17; 19.8 kJ/g), a high-fat diet (HFD; 41:16:43; 21.4kJ/g) or a commercial Western diet (WD; $41: 19: 41 ; 21.5 \mathrm{~kJ} / \mathrm{g}$ ). There was no difference in body weight gain between GF and CV mice on the LFD. On the HFD, GF mice gained more body weight and body fat than $\mathrm{CV}$ mice, and had lower energy expenditure. GF mice on the WD gained significantly less body fat than GF mice on the HFD. GF mice on both HFD and WD showed increased intestinal mRNA expression of fasting-induced adipose factor/angiopoietin-like protein 4 (Fiaf/Angptl4), but they showed no major changes in circulating Fiaf/Angptl4 compared with CV mice. The faecal microbiota composition of the $\mathrm{CV}$ mice differed between diets: the proportion of Firmicutes increased on both HFD and WD at the expense of the Bacteroidetes. This increase in the Firmicutes was mainly due to the proliferation of one family within this phylum: the Erysipelotrichaceae. We conclude that the absence of gut microbiota does not provide a general protection from diet-induced obesity, that intestinal production of Fiaf/Angptl4 does not play a causal role in gut microbiota-mediated effects on fat storage and that diet composition affects gut microbial composition to larger extent than previously thought.
\end{abstract}

Obesity: Intestinal bacteria: High-fat diet: Angiopoietin-like protein 4: Energy metabolism

Obesity is a global epidemic with more than 300 million adults being clinically obese worldwide. It is associated with various disorders including CVD, type 2 diabetes and certain types of cancers. Obesity is most commonly caused by a combination of factors such as excessive consumption of energy-dense foods, lack of physical activity and genetic susceptibility. Recently, the intestinal microbiota has been identified as a factor that may contribute to obesity development in both mice and human subjects ${ }^{(1,2)}$. Obesity has been linked to changes in the relative proportions of the phyla Bacteroidetes and Firmicutes ${ }^{(3)}$, which account for more than $90 \%$ of all faecal bacteria ${ }^{(2)}$. Genetically obese leptindeficient $(o b / o b)$ mice harboured $50 \%$ fewer Bacteroidetes and correspondingly more Firmicutes than the corresponding wild-type mice which were lean ${ }^{(3)}$. Moreover, conventional (CV) mice accumulated more body fat than germ-free (GF) mice when fed a Western-style, high-fat, sugar-rich diet (WD) ${ }^{(4)}$. To explain these observations, intestinal bacteria were proposed to afford a more efficient energy harvest from the diet by converting non-digestible carbohydrates to SCFA. The microbiota was also suggested to cause a reduction of fasting-induced adipose factor (Fiaf), also known as angiopoietin-like protein 4 (Angptl4), a circulating inhibitor of lipoprotein lipase, and thereby to promote the storage of fatty acids released by lipoprotein lipase in host adipose tissue ${ }^{(4)}$.

We set out to define the exact role of the intestinal microbiota in diet-induced obesity in more detail. For this purpose, we first checked whether the alterations in microbial composition obtained for the leptin-deficient mice ${ }^{(3)}$ are also valid for wild-type mice, and can therefore be generalised. We fed GF and CV mice various diets, including a semi-synthetic high-fat diet (HFD), which we used previously to induce obesity $^{(5)}$, and we determined body weight gain, body fat, energy expenditure, respiratory quotient and composition of the gut microbiota. We also investigated whether the lipogenic effects of the various diets are reflected by changes in intestinal Fiaf/ Angptl4 mRNA and Fiaf/Angptl4 plasma concentrations in the $\mathrm{GF}$ or $\mathrm{CV}$ host, respectively. Here, we have reported that

Abbreviations: Angptl4, angiopoietin-like protein 4; CV, conventional; Fiaf, fasting-induced adipose factor; FISH, fluorescence in situ hybridisation; GF, germ-free;

HFD, high-fat diet; LFD, low-fat diet; SD, standard chow diet; TBS-T, Tris-buffered saline; TEE, total energy expenditure; WD, Western diet.

* Corresponding author: Professor Michael Blaut, fax +49 33200 88500, email blaut@ dife.de

$\dagger$ C. K. F. and N. H. contributed equally to this paper. 
GF mice are not generally protected from obesity, and that Fiaf does not appear to play a major role in gut microbiotamediated effects on fat storage.

\section{Materials and methods}

\section{Animal maintenance and experimental setup}

Male GF and $\mathrm{CV}$ C3H mice were purchased from Charles River (L'Arbresle, France). GF mice were maintained in positive-pressure isolators (Metall \& Plastik, Radolfzell, Germany). All experimental diets were irradiated $(25 \mathrm{kGy})$. Mice were housed individually in polycarbonate cages on irradiated wood chips at $22 \pm 2^{\circ} \mathrm{C}$ and at a relative air humidity of $55 \pm 5 \%$ on a $12 \mathrm{~h}$ light-dark cycle. They had free access to a standard chow diet (SD, Altromin fortified type 1310; Altromin, Lage, Germany) and autoclaved distilled water. Coprophagy was not prevented. Animal maintenance and experiments were approved by the animal welfare committee of the Ministry of Agriculture and Environment (State of Brandenburg, Germany).

Expt 1. GF and CV mice, 12 weeks of age $(n 7)$, were assigned either to a semi-synthetic low-fat diet (LFD) or to a $\operatorname{HFD}^{(5,6)}$ for 4 weeks (Table 1 ). Feed was provided in special containers that allowed the collection of spilled feed. Body weight was measured twice per week. Energy intake $\left(E_{\text {in }}\right)$ and energy loss via the faeces $\left(E_{\text {faeces }}\right)$ were determined during the first $3 \mathrm{~d}$ of the intervention phase (IKA-Calorimeter C5000; IKA-Werke GmbH and Company KG, Staufen, Germany). Food digestibility in percentage was calculated as $\left(E_{\text {in }}-E_{\text {faeces }}\right) / E_{\text {in }} \times 100$, and the digestible energy as $E_{\text {in }} \times$ food digestibility. Faecal samples were collected directly before intervention and in week 4 of the intervention phase to analyse the microbial community composition by $16 \mathrm{~S}$ rRNA-targeted flow cytometry-coupled fluorescence in situ hybridisation (FISH).

Table 1. Composition of the semi-synthetic diets (low-fat diet (LFD) and high-fat diet (HFD)) and the commercial Western diet (WD)

\begin{tabular}{lccc}
\hline & $\begin{array}{c}\text { LFD } \\
(\mathrm{g} / \mathrm{kg})^{*}\end{array}$ & $\begin{array}{c}\text { HFD } \\
(\mathrm{g} / \mathrm{kg})^{*}\end{array}$ & $\begin{array}{c}\text { WD } \\
(\mathrm{g} / \mathrm{kg}) \dagger\end{array}$ \\
\hline Casein & 410 & 180 & 236 \\
Wheat starch & 370 & 430 & - \\
Maize starch & - & - & 160 \\
Sucrose & 50 & 50 & 183 \\
Maltodextrin & - & - & 120 \\
Vegetable shortening, & - & - & 100 \\
$\quad$ hydrogenated & - & - & 100 \\
Beef tallow & 50 & 180 & - \\
Coconut oil & 10 & 10 & - \\
Thistle oil & 10 & 10 & - \\
Linseed oil & 30 & 70 & 40 \\
Cellulose & 70 & 70 & 61 \\
Others & 19.8 & 21.4 & 21.5 \\
Energy (kJ/g)§ & 41.7 & $16 \cdot 0$ & $18 \cdot 7$ \\
Protein (energy \%) & $41 \cdot 1$ & $41 \cdot 0$ & $40 \cdot 7$ \\
Carbohydrate (energy \%) & $17 \cdot 2$ & $43 \cdot 0$ & $40 \cdot 6$ \\
Fat (energy \%) & & & \\
\hline
\end{tabular}

* Diet components as described in Daenzer et al. ${ }^{(6)}$.

$\dagger$ Diet components as provided by the manufacturer (Harlan Teklad).

$\ddagger$ Among others minerals and vitamins.

$\S$ As defined by bomb calorimetry.
Expt 2. Twelve-week-old male GF and $\mathrm{CV}$ mice (n 5) were fed either a HFD or a commercial WD (TD96132; Harlan Teklad, Madison, WI, USA) for 4 weeks. Food digestibility and digestible energy were measured during the first $3 \mathrm{~d}$ of the intervention. At the end of the experiments, mice were anaesthetised, and blood was collected by cardiac puncture. Subsequently, the mice were killed by cervical dislocation. Organs were removed, weighed, frozen in liquid nitrogen and stored at $-80^{\circ} \mathrm{C}$. Faecal samples were collected and analysed by flow cytometry-coupled FISH as in Expt 1 .

Expt 3. Twelve-week-old CV mice ( $n$ 5) were fed three different diets for 4 weeks: HFD, WD or SD. Faecal samples were collected in week 3 of the feeding experiment, and the faecal SCFA concentrations were determined. One week later, the mice were killed, and the DNA extracted from the colonic contents was subjected to microbial community analysis based on $16 \mathrm{~S}$ rRNA gene sequencing.

\section{Body composition and energy expenditure}

Body composition was determined at the end of the dietary intervention (day 30) using quantitative magnetic resonance (Bruker's Minispec MQ10, Bruker Minispec, Houston, TX, USA) as described previously ${ }^{(7)}$. Lean body mass was calculated by subtracting body fat values obtained by quantitative magnetic resonance from body weight values obtained before quantitative magnetic resonance measurement. Total energy expenditure (TEE) was measured by indirect calorimetry as described earlier ${ }^{(7-9)}$ using an open respirometric system (gas analysers: Magnos 16 and Uras 14, Hartmann \& Braun, Frankfurt/Main, Germany). Microbial colonisation of GF mice during the calorimetry was prevented by using irradiated cages, cage lids and water flasks, and high efficiency particulate air filters on the air inlet of the cages. All the mice were unrestrained, and had free access to their respective diets and water. The respiratory quotient $\left(\mathrm{V}_{\mathrm{CO} 2}: \mathrm{V}_{\mathrm{O} 2}\right)$ and $\mathrm{TEE}(\mathrm{kJ} / \mathrm{d})$ were calculated as described previously ${ }^{(10)}$. Measurements were performed at $6 \mathrm{~min}$ intervals over a $23 \mathrm{~h}$ period. After calorimetric measurements, faecal samples were collected from GF mice, and were checked for bacterial contamination.

\section{Quantitative real-time PCR}

RNA was isolated from the mucosa of the lowest third of the small intestine and the epididymal white adipose tissue as described before ${ }^{(11)}$ with modifications as described by Weber et $a l .{ }^{(12)}$. Residual genomic DNA was removed using the Turbo DNA-free Kit (Applied Biosystems, Foster City, CA, USA; Ambion, Austin, TX, USA). Synthesis of complementary DNA was performed from $1 \mu \mathrm{g}$ of total RNA using the RevertAid H Minus First Strand complementary DNA Synthesis Kit (Fermentas, St Leon-Rot, Germany). Quantitative real-time PCR was performed on the Applied Biosystems 7900 HT Fast Real-Time PCR System (Applied Biosystems). The PCR mix ( $5 \mu \mathrm{l})$ contained TaqMan(R) Universal PCR Master Mix, No AmpErase(R) UNG (Applied Biosystems) and a complementary DNA amount corresponding to $5 \mathrm{ng}$ of RNA used for complementary DNA synthesis and gene-specific primer probe pairs (for Fiaf/Angptl4: forward 5'-GGGACCTTAACTGTGCCAAG-3', reverse 5'-CCGTGGGATAGAGTGGAAGT-3', 
probe 5'-6-FAM-CCACCAGCCACCAGAGAGGCT-TAMRA- $3^{\prime}$ and for 18S rRNA: forward $5^{\prime}$-ACCACATCCAAGGAAGGCAG- $3^{\prime}$, reverse $5^{\prime}$-TTTTCGTCACTACCTCCCC- $3^{\prime}$, probe 5'-6-FAM-AGGCGCGCAAATTACCCACTCCC-TAMRA-3'). Gene expression was calculated as $\Delta C_{\mathrm{T}}$ using $18 \mathrm{~S}$ rRNA as a reference, and was expressed relative to the GF HFD group normalised to a value of 1 .

\section{Immunological detection of fasting-induced adipose factor/ angiopoietin-like protein 4 in plasma}

Plasma samples were run on an SDS polyacrylamide gel (4\% stacking gel and $10 \%$ running gel), and were transferred to polyvinylidine fluoride membranes (Roti-PVDF; Carl Roth $\mathrm{GmbH}$, Karlsruhe, Germany). Unspecific antibody binding was blocked with $5 \%$ milk powder (Carl Roth $\mathrm{GmbH}$ ) in $0.1 \%$ Tween 20/Tris-buffered saline (TBS-T; 20 mM-Tris, $137 \mathrm{~mm}-\mathrm{NaCl}$ and $0.1 \%(\mathrm{v} / \mathrm{v})$ Tween 20, $(\mathrm{pH}$ 7.6)) for $60 \mathrm{~min}$ at room temperature. Membranes were incubated overnight at $4^{\circ} \mathrm{C}$ in $1 \%$ bovine serum albumin/TBS-T with rabbit anti-Fiaf/Angptl4 (final dilution 1:2000; Acris Antibodies $\mathrm{GmbH}$, Herford, Germany), washed four times in TBS-T and subsequently incubated for $1 \mathrm{~h}$ at room temperature with a horseradish peroxidase-conjugated secondary antibody, goat anti-rabbit-IgG in $1 \%$ bovine serum albumin/TBS-T (final dilution 1:2000; Cell Signaling Technology, Danvers, MA, USA). After four washing steps in TBS-T, the membranes were incubated for $5 \mathrm{~min}$ with Super Signal West Femto Maximum Sensitivity Substrate (Thermo Scientific, Waltham, MA, USA) at room temperature. Signals were detected with the UVIprochemi imaging system (Biometra, Goettingen, Germany), and were quantified using the BioDocAnalyze 2.46.8.1 Software (Biometra).

\section{Plasma analysis}

Glucose concentrations were determined with Contour glucose sticks (Bayer, Leverkusen, Germany). Insulin was analysed by an ultrasensitive ELISA (Insulin mouse ultrasensitive ELISA; DRG Instruments, Marburg, Germany).

\section{Liver TAG and glycogen analyses}

For TAG analysis, liver tissue was ground in liquid nitrogen to a homogenous powder. One hundred milligrams of tissue were homogenised in $5 \mathrm{ml}$ of $10 \mathrm{mM}$-sodium phosphate buffer, $\mathrm{pH}$ $7 \cdot 4$, containing $1 \mathrm{mM}-\mathrm{EDTA}$ and $1 \%$ polyoxyethylene 10 tridecyl ether using an Ultra-Turrax (IKA-Werke), and were centrifuged for $15 \mathrm{~min}$ at $23100 \mathrm{~g}$. The supernatant fraction was incubated at $70^{\circ} \mathrm{C}$ for $5 \mathrm{~min}$ and centrifuged again. TAG (triglyceride reagent; Sigma, St Louis, MO, USA) and protein contents (detergent compatible protein assay; BioRad, Hercules, CA, USA) were analysed in triplicates from the supernatant.

For glycogen analysis, $50 \mathrm{mg}$ of ground liver tissue were homogenised in $750 \mu \mathrm{l}$ of $0.1 \mathrm{M}-\mathrm{NaOH}$ using an UltraTurrax. The homogenate was incubated at $70^{\circ} \mathrm{C}$ for $45 \mathrm{~min}$ and centrifuged for $10 \mathrm{~min}$ at $4^{\circ} \mathrm{C}$ and $12400 \mathrm{~g}$. Glycogen (Starch Kit; R-Biopharm, Darmstadt, Germany) and protein contents (detergent compatible protein assay) were analysed in triplicates from the supernatant.
Quantification of faecal bacteria by fluorescence in situ hybridisation

Freshly collected faecal samples $(0.2 \mathrm{~g}$ wet weight $)$ were suspended in $1.8 \mathrm{ml}$ of PBS $(138 \mathrm{~mm}-\mathrm{NaCl}, 26.8 \mathrm{~mm}-\mathrm{KCl}$, $40.3 \mathrm{~mm}-\mathrm{Na}_{2} \mathrm{HPO}_{4}$ and $17.6 \mathrm{~mm}-\mathrm{KH}_{2} \mathrm{PO}_{4}$ (pH 7.4)), thoroughly vortexed for $5 \mathrm{~min}$ and centrifuged at $300 \mathrm{~g}$ for $1 \mathrm{~min}$ at $4^{\circ} \mathrm{C}$ to remove debris. The cells were fixed by addition of $1.5 \mathrm{ml}$ of $4 \%$ paraformaldehyde solution to $500 \mu \mathrm{l}$ of cell suspension and subsequent storage at $4^{\circ} \mathrm{C}$ for $3 \mathrm{~h}$. Fixed bacterial cells were kept at $-80^{\circ} \mathrm{C}$ until analysis. For analysis, the paraformaldehyde-fixed cells were thawed and hybridised with 16S rRNA-targeted oligonucleotide probes. The probes used were EUB338 for the detection of total bacteria ${ }^{(13)}$, non-Eub338 for quantifying unspecific binding of the fluorochrome ${ }^{(14)}$, Bac303 for the detection of Bacteroides $^{(15)}$, Erec 482 for the detection of the Eubacterium rectale-Clostridium coccoides cluster ${ }^{(16)}$, Lab158 for the detection of Lactobacillus/Enterococcus spp. ${ }^{(17)}$ and Clep866, which was used in conjunction with the two competitor probes cpClep1 and cpClep2, for the detection of the Clostridium leptum group ${ }^{(18)}$. The probes were covalently linked at their $5^{\prime}$-end to either fluorescein isothiocyanate or indodicarbocyanine. Following hybridisation, a 100- $\mu$ l aliquot of each cell suspension was added to $250 \mu \mathrm{l}$ FACSFlow (Becton Dickinson, Pont de Claix, France) for flow cytometric detection. Data acquisition was performed with a FACSCalibur flow cytometer (Becton Dickinson) equipped with an aircooled argon ion laser providing $15 \mathrm{~mW}$ at $488 \mathrm{~nm}$ combined with a $635 \mathrm{~nm}$ red-diode laser as described previously ${ }^{(19)}$. All parameters were collected as logarithmic signals. A total of $10^{5}$ events were stored in listmode files. The rate of events in the flow was generally approximately 3000 counts/s.

\section{Bacterial community analysis based on $16 S$ rRNA gene sequencing}

Bacterial DNA was isolated from colonic contents using the FastDNA $^{\circledR}$ SPIN Kit (MP Biomedicals, Eschwege, Germany) according to the manufacturer's instructions. Isolated DNA was pooled from five mice per dietary group. The $16 \mathrm{~S}$ rRNA genes were amplified using the 1492 reverse primer $\left(5^{\prime}\right.$-TACCTTGTTACGACTT- $\left.3^{\prime}\right)$ and a mixture of the following twenty-seven forward primers ${ }^{(20)}: 27 \mathrm{f}$-Bif, $5^{\prime}$-AGGGTTCGATTCTGGCTCAG-3', Bifidobacteriaceae; 27f-Bor, 5'-AGAGTTTGATCCTGGCTTAG-3', Borrelia; 27f-Chl, 5'-AGAATTTGATCTTGGTTCAG-3', Chlamydiales; and 27f-YM, 5'-AGAGTTTGATYMTGGCTCAG- $3^{\prime}$, where $\mathrm{Y}$ is $\mathrm{C}$ or $\mathrm{T}$, and $\mathrm{M}$ is $\mathrm{A}$ or $\mathrm{C}$. The PCR mixture $(50 \mu \mathrm{l})$ contained $50 \mathrm{~mm}-\mathrm{KCl}, 20 \mathrm{~mm}-\mathrm{Tris}-\mathrm{HCl}, 2.5 \mathrm{~mm}-\mathrm{MgCl}_{2}, 0.25 \mathrm{~mm}$ of each deoxyribonucleotide triphosphate, $0.2 \mu \mathrm{M}$ of each primer, $2.5 \mu \mathrm{mol} / \mathrm{min}$ of Taq DNA polymerase (Invitrogen, Karlsruhe, Germany) and $1 \mu l$ of template DNA. The PCR program was $94^{\circ} \mathrm{C}$ for $4 \mathrm{~min}$, thirty cycles of $94^{\circ} \mathrm{C}$ for $30 \mathrm{~s}$, $54^{\circ} \mathrm{C}$ for $30 \mathrm{~s}$ and $72^{\circ} \mathrm{C}$ for $30 \mathrm{~s}$, and finally one cycle of $72^{\circ} \mathrm{C}$ for $2 \mathrm{~min}$. PCR products were ligated into the vector pGEM-T Easy (Promega, Mannheim, Germany), and were transformed into Escherichia coli JM109. For each diet, approximately 170 colonies containing cloned amplicons were processed for sequencing. Plasmid inserts were sequenced unidirectionally by Eurofins MWG Operon (Eberswalde, Germany) using the 
vector-specific primer SP6. Using the Basic Local Alignment Search Tool (BLAST, http://blast.ncbi.nlm.nih.gov/Blast.cgi), the obtained $16 \mathrm{~S}$ rRNA gene sequences were compared against the sequence database. Only sequences with a length $>750 \mathrm{bp}$ were considered. The taxonomic assignment given in Table 5 is based on the phylogenetic position of the most closely related species $(>96 \%)$.

\section{Analysis of faecal SCFA}

Faecal acetate, butyrate, propionate, valerate and isovalerate were measured with an HP 5890 series II gas chromatograph (Hewlett-Packard, Waldbronn, Germany) equipped with an HP-20 M column and a flame ionisation detector. Fresh faeces were fivefold diluted with water and centrifuged at $21000 \mathrm{~g}$ for $5 \mathrm{~min}$. Supernatant $(200 \mu \mathrm{l})$ was mixed with $23.6 \mu \mathrm{l}$ of $12 \mathrm{~mm}$-isobutyric acid, $270 \mu \mathrm{l}$ of $1 \mathrm{M}-\mathrm{NaOH}$ and $280 \mu \mathrm{l}$ of $0.36 \mathrm{M}-\mathrm{HClO}_{4}$. The mixture was lyophilised overnight, and the remnant was re-dissolved in a mixture of $400 \mu \mathrm{l}$ of acetone and $100 \mu \mathrm{l}$ of $5 \mathrm{M}$-formic acid. After centrifugation, $1 \mu \mathrm{l}$ of the supernatant was injected into the gas chromatograph.

\section{Statistical analysis}

Data are presented as means with their standard errors. Differences between groups were analysed using ANOVA (two-factorial or repeated measurements when appropriate) followed by the Bonferroni post-test analysis (Prism 4.0 for Windows, Graph Pad Software, Inc., La Jolla, CA, USA). Differences were considered significant at $P<0 \cdot 05$. Differences in the microbiological data within the groups at baseline and after intervention were analysed using the Wilcoxon signed rank test. Differences between the dietary groups during the intervention were analysed using the Mann-Whitney $U$ test.

\section{Results}

Expt 1

To better define the possible role of intestinal bacteria in diet-induced obesity, we first investigated whether the previously reported protection of GF mice from obesity ${ }^{(4)}$ is generally valid. If this was the case, this protection should not be restricted to a certain type of HFD. Therefore, GF and CV wild-type mice ( $n$ 14), previously kept on SD, were fed for 4 weeks either one of the two experimental semisynthetic diets $(n 7)$ : a LFD and a HFD ${ }^{(5)}$. The mean body weight at the start of the dietary intervention period was 29.3 (SEM 0.3) $\mathrm{g}$ for the GF mice and 27.5 (SEM 0.2) $\mathrm{g}$ for the $\mathrm{CV}$ mice $(P<0 \cdot 001)$. GF and $\mathrm{CV}$ mice fed the LFD had essentially the same body weight gain over the 4-week intervention period (GF LFD 2.0 (SEM 0.3) g and CV LFD 1.8 (SEM 0.4) g per animal per 4 weeks). In contrast, GF mice fed the HFD gained more body weight than $\mathrm{CV}$ mice fed the HFD (Fig. 1(A), $P<0 \cdot 001$ ). These differences in body weight gain after 4 weeks on the HFD are consistent with differences in the body fat content, which was more than twofold higher in GF mice than in CV mice (Fig. 1(B), $P<0 \cdot 001$ ). There was no significant difference in lean mass between $\mathrm{CV}$ and GF mice, neither on the LFD nor on the HFD (Table 2).

During the first $3 \mathrm{~d}$ of the 4-week intervention period, we also measured food digestibility and total digestible energy. The digestibility of the LFD and the HFD was $>90 \%$ in both $\mathrm{CV}$ and GF mice (Table 2). The total digestible energy did not differ between CV and GF mice, neither on the LFD nor on the HFD. After 4 weeks of dietary intervention, we measured the TEE of the mice. The daily patterns of TEE in GF and CV mice fed the LFD (data not shown) and in the $\mathrm{CV}$ mice fed the HFD were similar (Fig. 2). In contrast, GF mice fed the HFD had a lower TEE than CV mice fed the HFD, in particular during the dark phase (i.e. activity period) and when normalised for body weight (Table 2). The respiratory quotient, an indicator of the overall substrate
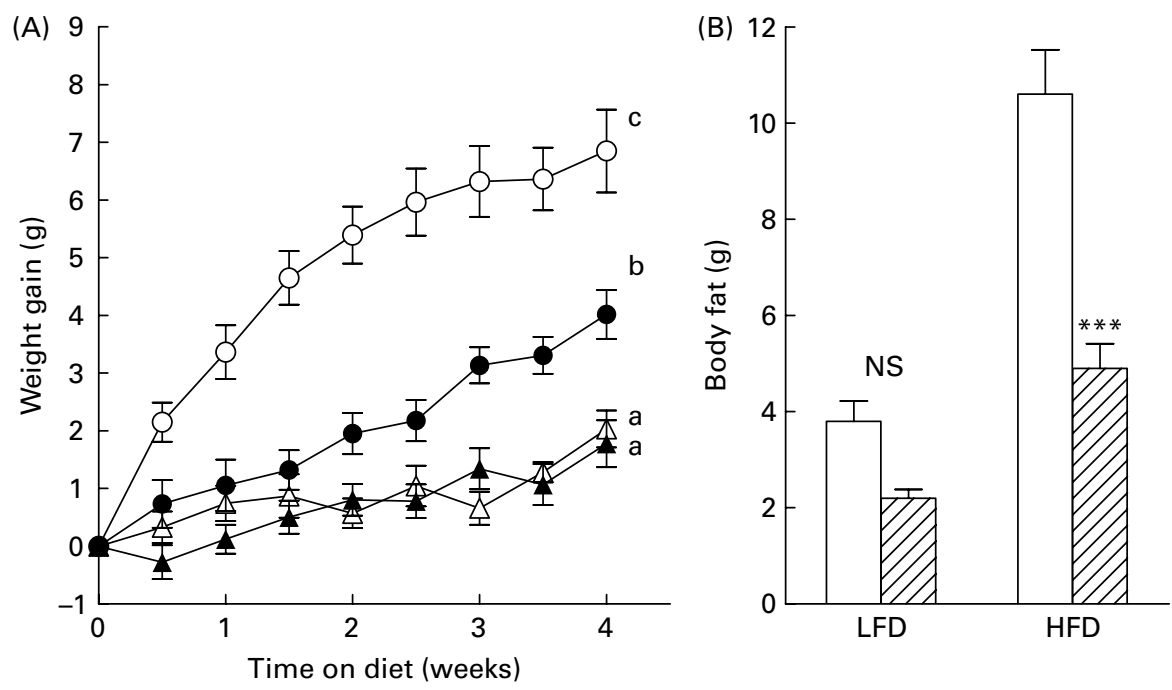

Fig. 1. Weight gain (A) and body fat (B) of conventional (CV) and germ-free (GF) mice after 4 weeks on the semi-synthetic low-fat diet (LFD) and the high-fat diet (HFD), respectively. Mean values with their standard errors are plotted, $n$ 7. ${ }^{a, b, c}$ Mean values at week 4 with unlike letters were significantly different $(P \leq 0.05) .{ }^{* * *}$ Mean values were significantly different compared with GF mice $(P<0.001)$. (A) $-\triangle-$, GF LFD; $-O-$, GF HFD; $-\Delta-$, CV LFD; $-\bullet-$, CV HFD. (B) $\square$, GF; 四, CV. 


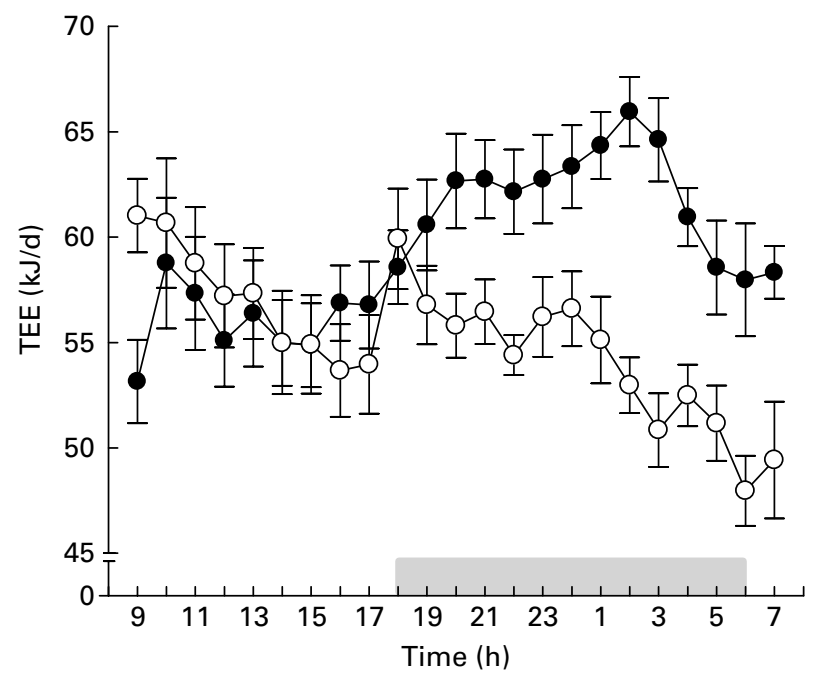

Fig. 2. Twenty-three-hour total energy expenditure (TEE) of conventional $(\bullet)$ and germ-free $(O)$ mice after 4 weeks on the semi-synthetic high-fat diet. The grey bar indicates night time (lights off). Values are means with their standard errors $(n 7)$. For statistical analysis, see Table 2.

oxidation $^{(21)}$, was higher for mice fed the LFD than for those fed the HFD, no matter whether the mice were GF or CV. This indicates that the LFD leads to a higher overall carbohydrate oxidation. Since there were no significant differences in digestible energy, we propose that the low energy expenditure of GF mice on the HFD is a major factor that contributes to the higher accumulation of body fat in this group.

To assess the impact of the two experimental diets on the gut microbial community of the CV mice, we collected faeces before and after the dietary intervention, and determined by flow cytometry-coupled FISH the proportions of four major phylogenetic groups representative of the two dominant phyla in the mouse intestine: the phylum Bacteroidetes was represented by the Bacteroides-Prevotella group, and the phylum Firmicutes was represented by the E. rectale-C. coccoides cluster, the Lactobacillus-Enterococcus group and the $C$. leptum group. These four bacterial groups accounted at baseline (SD) for approximately $75 \%$ of total bacterial cells detectable with the EUB338 probe, while they accounted for only 51.5 (SEM 4.6) \% when fed the LFD and 27.2 (SEM 7.2) \% when fed the HFD (Table 3; Expt 1), indicating that the proportion of bacteria detectable with the selected probes decreased in response to the semi-synthetic diets.

\section{Expt 2}

The afore-mentioned results appeared to be in conflict with the observations and conclusions of Backhed et al. ${ }^{(4)}$ who reported that GF mice but not $\mathrm{CV}$ mice are protected from diet-induced obesity. These authors used a commercial semisynthetic HFD, referred to as WD. While the macronutrient compositions of WD and HFD are almost identical, they differ in the type of carbohydrates and lipids (Table 1). To further test the hypothesis that GF mice are not generally protected from obesity, we performed a second feeding experiment, in which we compared the effects of HFD and WD on weight gain and body fat of GF and $\mathrm{CV}$ mice $(n 5)$. In the course of the dietary intervention, GF mice gained 
Table 3. Proportions of bacterial groups determined by flow cytometry-coupled fluorescence in situ hybridisation in the faeces of conventional mice at baseline and in response to different diets in week 4 of the intervention phase* (Mean values with their standard errors; Expt 1, $n$ 7; Expt 2, $n$ 5)

\begin{tabular}{|c|c|c|c|c|c|c|c|c|c|c|}
\hline \multirow[b]{4}{*}{ Expt 1} & \multicolumn{10}{|c|}{ Relative proportion (\% of EUB338) } \\
\hline & \multicolumn{6}{|c|}{ Baseline (SD) } & \multicolumn{4}{|c|}{ Intervention } \\
\hline & \multicolumn{2}{|c|}{ Group 1} & \multicolumn{2}{|c|}{ Group 2} & \multicolumn{2}{|c|}{ Groups $1+2$} & \multicolumn{2}{|c|}{ LFD (group 1) } & \multicolumn{2}{|c|}{ HFD (group 2) } \\
\hline & Mean & SEM & Mean & SEM & Mean & SEM & Mean & SEM & Mean & SEM \\
\hline Вас303 & $9 \cdot 0$ & 1.9 & 6.4 & 1.2 & $7 \cdot 7$ & $1 \cdot 6$ & $32 \cdot 2 \dagger$ & $2 \cdot 3$ & $2 \cdot 4 † \ddagger$ & $1 \cdot 0$ \\
\hline Erec482 & $45 \cdot 0$ & 3.3 & $45 \cdot 6$ & 4.4 & $45 \cdot 3$ & 3.7 & $12.2 \dagger$ & $1 \cdot 1$ & $21 \cdot 3 † \ddagger$ & $5 \cdot 3$ \\
\hline Lab158 & $22 \cdot 6$ & 3.5 & 18.4 & $2 \cdot 3$ & $20 \cdot 5$ & 2.9 & $3.5 \dagger$ & 0.7 & 3.5 & $0.9 \dagger$ \\
\hline Clep866 & $2 \cdot 0$ & 0.2 & 1.5 & 0.8 & $1 \cdot 8$ & 0.5 & $3.6 \dagger$ & 0.5 & - & \\
\hline \multirow[t]{2}{*}{ Total } & 78.6 & 8.9 & 71.9 & $8 \cdot 7$ & $75 \cdot 3$ & $8 \cdot 8$ & $51.5 \dagger$ & $4 \cdot 6$ & $27 \cdot 2 † \ddagger$ & $7 \cdot 2$ \\
\hline & \multicolumn{2}{|c|}{ Group 1} & \multicolumn{2}{|c|}{ Group 2} & \multicolumn{2}{|c|}{ Groups $1+2$} & \multicolumn{2}{|c|}{ HFD (group 1) } & \multicolumn{2}{|c|}{ WD (group 2) } \\
\hline Expt 2 & Mean & SEM & Mean & SEM & Mean & SEM & Mean & SEM & Mean & SEM \\
\hline Вас303 & $10 \cdot 4$ & 1.6 & $13 \cdot 2$ & 1.5 & $11 \cdot 8$ & 1.6 & $2 \cdot 8 \dagger$ & 0.3 & $2 \cdot 1 \dagger$ & $1 \cdot 3$ \\
\hline Erec482 & $41 \cdot 0$ & $2 \cdot 0$ & $38 \cdot 2$ & $1 \cdot 1$ & $39 \cdot 6$ & $1 \cdot 6$ & $22.4 \dagger$ & 1.9 & $12 \cdot 2 \dagger \ddagger$ & 1.5 \\
\hline Lab158 & $26 \cdot 5$ & $1 \cdot 8$ & $22 \cdot 8$ & 3.9 & $24 \cdot 7$ & $2 \cdot 9$ & $2 \cdot 1 \dagger$ & 0.4 & $2.9 \dagger$ & 0.5 \\
\hline Clep866 & $1 \cdot 8$ & 0.1 & $2 \cdot 0$ & 0.1 & 1.9 & 0.1 & - & & $1.9 \dagger$ & 0.3 \\
\hline Total & 79.7 & 5.5 & $76 \cdot 2$ & $6 \cdot 6$ & 78.0 & $6 \cdot 1$ & $27.3 \dagger$ & $2 \cdot 6$ & $19 \cdot 1 \dagger \ddagger$ & $3 \cdot 6$ \\
\hline
\end{tabular}

SD, standard chow diet; LFD, low-fat diet; HFD, high-fat diet; WD, Western diet

* One sample of each animal was analysed in duplicates before and at the end of the intervention.

$\dagger$ Mean values were significantly different between baseline and intervention for a given group $(P<0.05)$.

$\ddagger$ Mean values were significantly different between dietary groups during intervention $(P<0.05)$.

significantly more weight on the HFD than on the WD $(P<0 \cdot 01)$ and, accordingly, at the end of the intervention period, they had $68 \%$ more body fat on the HFD than on the WD (Table 4).

In agreement with the experiments of Backhed et al. ${ }^{(4)}$, GF mice fed the WD had $41 \%$ less body fat than CV mice fed the WD $(P<0 \cdot 05$, Table 4$)$. In contrast, GF mice fed the HFD had body fat content that was similar to that of $\mathrm{CV}$ mice fed this diet, and the weight gain of the GF mice and the CV mice on this diet was also similar. The latter finding differs from that in the first experiment, in which GF mice gained more weight than $\mathrm{CV}$ mice and had more body fat when fed the HFD. Nevertheless, both the experiments consistently showed that GF mice fed the HFD did not have less body fat than the corresponding $\mathrm{CV}$ mice. These data clearly demonstrate that GF mice are not generally protected from obesity, but that the actual components of the diet rather than the macronutrient composition determine the extent of protection. The differences in weight gain and body fat observed from the comparison of the HFD-fed GF and CV

Table 4. Biometric parameters, liver biochemistry and plasma parameters of germ-free (GF) and conventional (CV) mice fed high-fat diet (HFD) or Western diet (WD) for 4 weeks (Expt 2)

(Mean values with their standard errors, $n 5$ )

\begin{tabular}{|c|c|c|c|c|c|c|c|c|c|c|c|}
\hline & \multicolumn{4}{|c|}{ HFD } & \multicolumn{4}{|c|}{ WD } & & & \\
\hline & \multicolumn{2}{|c|}{ GF } & \multicolumn{2}{|c|}{ CV } & \multicolumn{2}{|c|}{ GF } & \multicolumn{2}{|c|}{$\mathrm{CV}$} & \multicolumn{3}{|c|}{ ANOVA } \\
\hline & Mean & SEM & Mean & SEM & Mean & SEM & Mean & SEM & Status & Diet & Status $\times$ diet \\
\hline BW (week 0; g) & $24 \cdot 3$ & 0.5 & $28 \cdot 2^{\star \star}$ & 0.6 & $24 \cdot 3$ & 1.3 & $28 \cdot 2^{\star \star}$ & 0.5 & 0.0001 & NSt & NS† \\
\hline BW (week 4; g) & $30 \cdot 4$ & 0.4 & $34 \cdot 4^{\star *}$ & 0.9 & $27 \cdot 2$ & 1.4 & $32 \cdot 6^{\star \star \star}$ & 0.3 & $<0.0001$ & 0.0095 & NS† \\
\hline Fat mass (week 4; g) & $7 \cdot 3$ & 0.6 & $8 \cdot 7$ & 0.6 & $4 \cdot 3$ & $1 \cdot 2$ & $7 \cdot 4^{*}$ & 0.3 & 0.0087 & 0.0121 & NSt \\
\hline $\begin{array}{l}\text { Fat mass (week } 4 ; \% \text { of } \\
\text { BW week 4) }\end{array}$ & $23 \cdot 9$ & $1 \cdot 9$ & $25 \cdot 2$ & $1 \cdot 3$ & $15 \cdot 4$ & $3 \cdot 2$ & $22 \cdot 8^{*}$ & 0.9 & 0.0466 & 0.0152 & NSt \\
\hline Weight gain $(\mathrm{g})$ & $6 \cdot 1$ & 0.8 & $6 \cdot 2$ & 0.7 & $2 \cdot 9$ & 0.2 & 4.4 & 0.2 & NS† & 0.0003 & NS† \\
\hline $\begin{array}{l}\text { Weight gain (week } 0 ; \\
\% \text { of BW) }\end{array}$ & $25 \cdot 5$ & $3 \cdot 8$ & $21 \cdot 8$ & $2 \cdot 3$ & $11 \cdot 8$ & $1 \cdot 1$ & $15 \cdot 6$ & 0.8 & NSt & 0.0006 & NSt \\
\hline $\begin{array}{l}\text { Liver weight (week } 4 \text {; } \\
\% \text { of BW) }\end{array}$ & 4.43 & 0.08 & 4.63 & 0.09 & $4 \cdot 47$ & $0 \cdot 10$ & $5 \cdot 12^{\star \star \star}$ & 0.06 & 0.0001 & 0.0056 & 0.0175 \\
\hline Liver TAG (mg/g tissue) & $110 \cdot 1$ & $22 \cdot 7$ & $106 \cdot 2$ & $10 \cdot 3$ & $118 \cdot 8$ & $12 \cdot 6$ & $201 \cdot 4^{\star \star}$ & $9 \cdot 6$ & 0.0199 & 0.0037 & 0.0119 \\
\hline Liver glycogen (mg/g tissue) & $17 \cdot 8$ & 1.7 & $27 \cdot 6^{\star}$ & 1.9 & 11.8 & $2 \cdot 8$ & $26 \cdot 1^{\star \star \star}$ & $2 \cdot 4$ & $<0.0001$ & NS† & NS† \\
\hline Plasma glucose $(\mathrm{mmol} / \mathrm{l})$ & $6 \cdot 1$ & 0.3 & $7 \cdot 6^{\star \star}$ & 0.4 & 4.9 & 0.3 & $6 \cdot 6^{* *}$ & 0.2 & $<0.0001$ & 0.0019 & NSt \\
\hline Plasma insulin $(\mu \mathrm{g} / \mathrm{l})$ & 0.73 & 0.25 & 1.55 & 0.31 & 0.79 & $0 \cdot 16$ & $2 \cdot 01^{\star \star}$ & $0 \cdot 13$ & 0.0004 & NS† & NS† \\
\hline
\end{tabular}

BW, body weight.

Mean values were significantly different compared with GF mice on the same diet: ${ }^{\star} P<0.05,{ }^{\star \star} P<0.01,{ }^{\star \star \star} P<0.001$.

$\dagger P>0.05$. 
mice between Expt 1 and 2 might be due to accidental differences at the start of the dietary intervention: in Expt 1, the initial body weight was higher for the GF mice than for the CV mice on the HFD (CV mice 27.5 (SEM 0.2) $\mathrm{g}$ and GF mice 29.3 (SEM 0.3) g, $P<0.001$ ), while the opposite was true in Expt 2 (CV mice 28.2 (SEM 0.3) g and GF mice $24 \cdot 3$ (SEM 0.6) g, $P<0 \cdot 001$ ).

There was no significant difference in lean mass between GF mice fed the HFD and GF mice fed the WD (data not shown). The digestibility of the WD was similar in GF and CV mice (92.1 (SEM 0.31) and 92.1 (SEM 0.27) \%, respectively), and intake of digestible energy in the first $3 \mathrm{~d}$ of the dietary intervention phase was also not different between GF and CV mice (85.0 (SEM 3.4) and 83.6 (SEM 2.6) kJ/d, respectively). These findings suggest that the WD but not the HFD rendered GF mice in comparison with $\mathrm{CV}$ mice less sensitive to the induction of obesity. However, this 'resistance' of GF mice fed the WD was not due to an impaired ability to digest this particular diet. While plasma glucose, plasma insulin and liver glycogen concentrations were lower in GF mice on both the diets, we observed a significant difference in liver TAG concentrations between GF and CV mice only on the WD, with increased liver TAG in CV mice but not in GF mice (Table 4).

It has been proposed that the intestinal microbiota promotes fat storage of the host by suppressing the intestinal expression of Fiaf/Angptl4, a circulating lipoprotein lipase inhibitor ${ }^{(4,22)}$. To find out whether the differential effects of the two HFD are mediated by changes in intestinal Fiaf/Angptl4, we measured the corresponding mRNA concentrations in GF and $\mathrm{CV}$ mice after 4 weeks on LFD, HFD and WD, respectively (Fig. 3(a) and (b)). In all the diet groups, we observed higher expression of Fiaf/Angptl4 mRNA in the mucosa of the distal small intestine of GF mice than of CV mice. As Fiaf/Angptl4 is a secreted protein, we also determined its plasma concentrations (Fig. 3(c)). Contrary to the increased intestinal mRNA concentrations, GF mice did not show higher concentrations of any of the three Fiaf/Angptl4 forms detectable in murine plasma (native Fiaf/Angptl4, S2 form and $\mathrm{S} 1$ form) on any of the diets. CV mice even showed a slightly increased Fiaf/Angptl4 S2 concentration on any of the diets (approximately 2-fold that of GF mice on LFD and $1 \cdot 3$-fold on HFD and WD, $P<0.05$ ). The differences in the Fiaf/Angpt14 S2 concentrations between the diets were modest and NS, neither in GF mice (LFD approximately 0.91 WD approximately 0.81 HFD) nor in CV mice (LFD approximately 0.94 WD approximately 0.84 HFD). Using the same antibody, we failed to detect any Fiaf/Angptl4 in the intestinal mucosa of both GF and CV mice (data not shown). This suggests that the intestinal production of Fiaf/ Angptl4 does not contribute significantly to circulating Fiaf/ Angptl4 concentrations.

The faecal microbiota analysed in the CV mice by flow cytometry-coupled FISH at baseline and during the 4-week dietary intervention revealed changes in response to this intervention: the proportion of faecal bacteria detectable with the four selected probes was considerably higher at baseline (SD) $(79.7$ (SEM 5.5) \% for group 1 (HFD) and 76.2 (SEM 6.6) $\%$ for group 2 (WD)) than during the intervention phase when the mice received either one of the two semi-synthetic high-fat diets (HFD: 27.3 (SEM 2.6)\% or WD: 19.1 (SEM $3.6) \%$ ). These observations were in accordance with those made in Expt 1 (Table 3), and they suggested that bacteria not detectable with the selected probes had increased at the expense of those targeted by these probes.

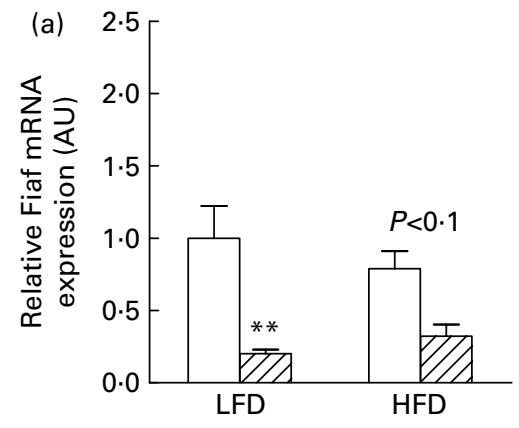

(c)
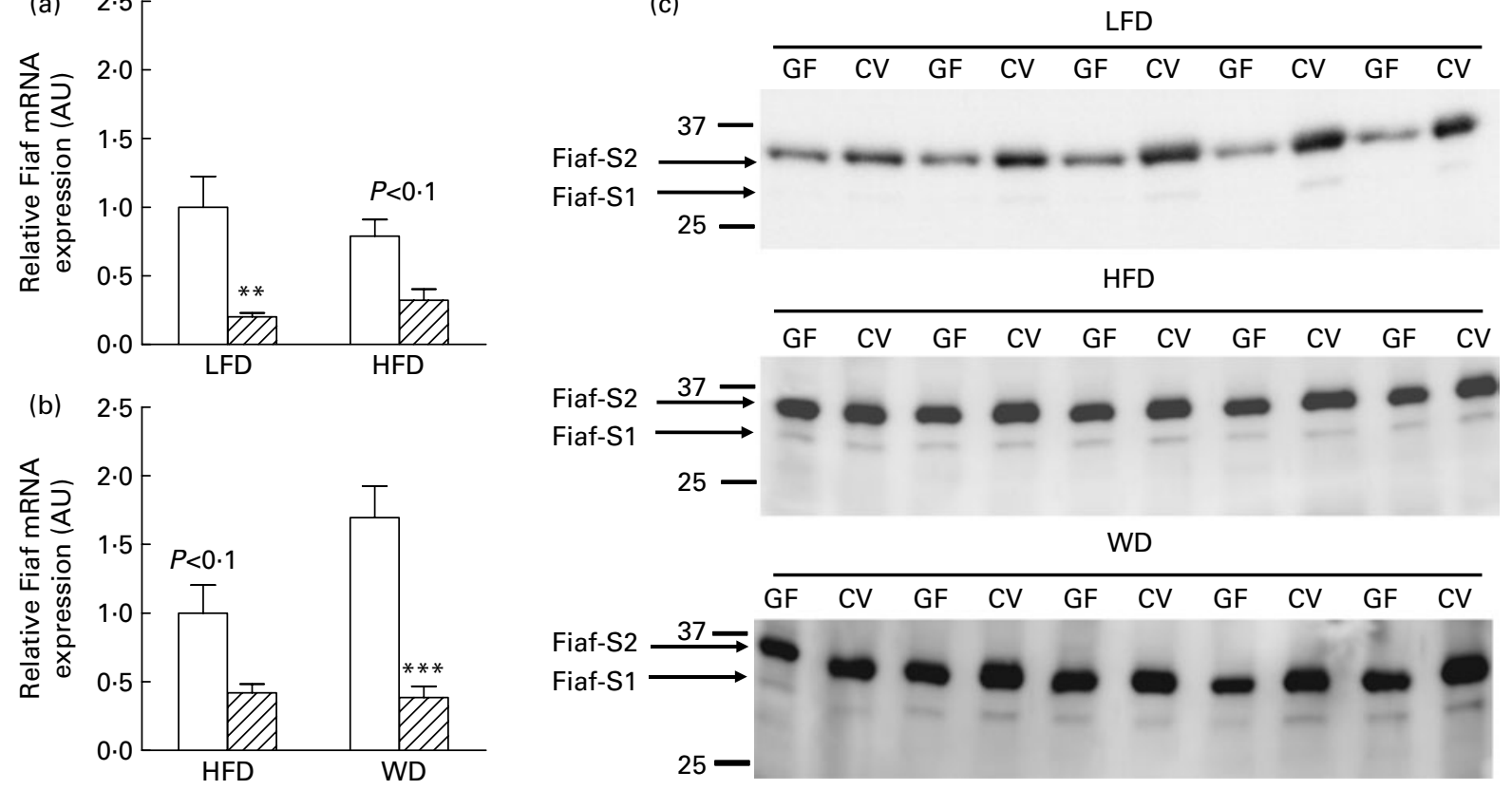

Fig. 3. Intestinal fasting-induced adipose factor (Fiaf/angiopoietin-like protein 4 (Angpt/4)) mRNA and plasma protein concentrations of mice fed the low-fat or two different high-fat diets for 4 weeks. Quantitative real-time PCR assays of Fiaf/Angptl4 expression in the distal small intestines of germ-free (GF, $\square$ ) and conventional $(\mathrm{CV}, 0)$ mice from Expt $1(\mathrm{a}, n 7)$ and Expt $2(\mathrm{~b}, n 5)$. Mean values with their standard errors are plotted. Mean values were significantly different compared with GF mice on the same diet: ${ }^{\star *} P<0.01,{ }^{* *} P<0.001$. (b) Western blots of plasma from GF and CV mice fed the low-fat diet (LFD), high-fat diet (HFD) or the Western diet (WD) using anti-mFiaf antibody. The two truncated N-terminal Fiaf/Angptl4 forms, S1 and S2, are visible. Visualisation of the native form needed longer exposure times (not shown). In each lane, $0.4 \mu \mathrm{l}$ plasma was loaded. AU, arbitrary units. 


\section{Expt 3}

To investigate the dietary effects on the gut microbiota in more detail, we performed a third feeding experiment, in which we compared three groups of CV mice $(n$ 5) fed either one of the three diets for four weeks: SD, HFD or WD. Weight gain and body fat content of the mice fed the HFD or the WD were significantly higher than those of the mice fed the SD. In accordance with Expt 2, the body fat content of mice fed the HFD was significantly higher than that of mice fed the WD (Fig. 4). The pooled DNA from colonic contents of each of the three dietary groups was subjected to $16 \mathrm{~S}$ rRNA gene sequence-based bacterial population analysis. The majority $(94 \%)$ of the $16 \mathrm{~S}$ rRNA gene sequences (approximately 170 per diet) were attributable to Bacteroidetes and Firmicutes (Table 5). Mice on the HFD and WD harboured in addition sequences attributable to Proteobacteria and Deferribacteriaceae, none of which is detectable by any of the four group-specific probes used in the flow cytometric analysis in Expt 1 and 2. The percentage of Bacteroidetes on the HFD $(5.4 \%)$ and WD $(5.5 \%)$ was approximately threefold lower than that of Bacteroidetes on the SD $(15.5 \%)$. The three dietary groups differed substantially in the proportion of sequences belonging to the Erysipelotrichaceae, a family within the phylum Firmicutes, which are also not detectable with any of the group-specific probes used in Expt 1 and 2 . On the HFD and the WD, the Erysipelotrichaceae sequences accounted for approximately 55 and $26 \%$, respectively, of the Firmicutes sequences, but for only $8 \%$ on the SD (Table 5). This is in agreement with a recent study ${ }^{(23)}$, which reported the bloom of a single class of the Firmicutes in the mouse intestine in response to adipogenic diets.

The faecal concentrations of acetate, propionate and butyrate were 2.5- to 5-fold lower for mice fed the adipogenic HFD or WD than for mice fed the SD (Table 6). In contrast, Schwiertz et al. ${ }^{(24)}$ observed higher faecal propionate concentrations in overweight and obese human subjects. Our findings do not support the notion that higher SCFA concentrations are responsible for the increased weight and body fat observed in the mice fed the HFD or the WD.

\section{Discussion}

Recent reports indicate that the intestinal microbiota plays a role in the development of diet-induced obesity. However,
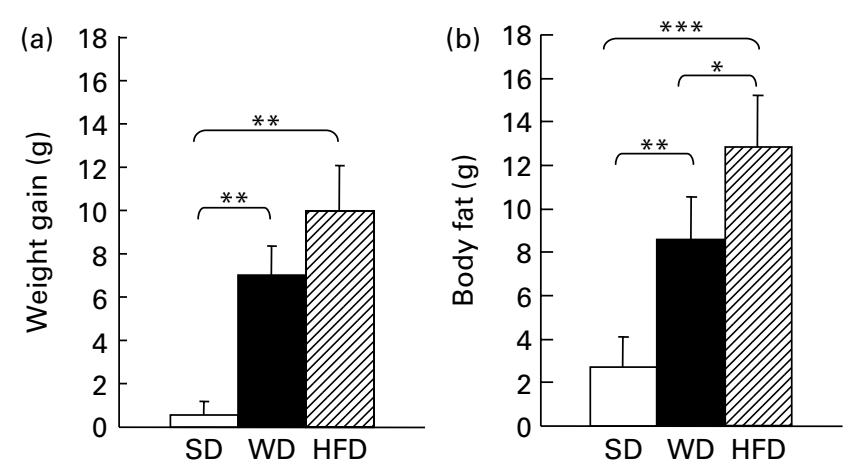

Fig. 4. Weight gain (a) and body fat (b) of conventional mice fed standard chow diet (SD), high-fat diet (HFD) or Western diet (WD) $(n 5)$ for 4 weeks. ${ }^{*} P<0.05,{ }^{* *} P<0.01$, ${ }^{\star * *} P<0.001$.
Table 5. Taxonomy-based analysis of 16S rRNA gene sequences of pooled colonic contents of conventional mice fed different diets for 4 weeks

\begin{tabular}{|c|c|c|c|}
\hline & \multicolumn{3}{|c|}{$\begin{array}{l}\text { Relative proportion } \\
\text { (\% of total sequences) }\end{array}$} \\
\hline & SD & HFD & WD \\
\hline Bacteria & $100 \cdot 0^{*}$ & $100 \cdot 0 \dagger$ & $100 \cdot 0 \ddagger$ \\
\hline Firmicutes & 84.5 & 88.6 & 80.5 \\
\hline Lactobacillaceae & $49 \cdot 7$ & $7 \cdot 1$ & $29 \cdot 4$ \\
\hline Erysipelotrichaceae & $6 \cdot 8$ & $48 \cdot 8$ & $20 \cdot 8$ \\
\hline Lachnospiraceae & $7 \cdot 7$ & $1 \cdot 8$ & $7 \cdot 2$ \\
\hline Ruminococcaceae & $1 \cdot 2$ & $7 \cdot 7$ & $3 \cdot 8$ \\
\hline Peptostreptococcaceae & - & - & 0.5 \\
\hline Enterococcaceae & - & 0.6 & $3 \cdot 8$ \\
\hline Clostridiaceae & $12 \cdot 3$ & 14.9 & $5 \cdot 0$ \\
\hline Bacillaceae & $5 \cdot 6$ & $3 \cdot 6$ & - \\
\hline Streptococcaceae & 0.6 & $1 \cdot 2$ & $10 \cdot 0$ \\
\hline Blautia & 0.6 & 2.9 & - \\
\hline Bacteroidetes & $15 \cdot 5$ & $5 \cdot 4$ & $5 \cdot 5$ \\
\hline Bacteroidaceae & 9.9 & $5 \cdot 4$ & $5 \cdot 0$ \\
\hline Porphyromonadaceae & 2.4 & - & - \\
\hline Rikenellaceae & $3 \cdot 2$ & - & 0.5 \\
\hline Prevotellaceae & - & - & - \\
\hline Proteobacteria & - & 0.6 & $6 \cdot 8$ \\
\hline Enterobacteriaceae & - & 0.6 & $6 \cdot 8$ \\
\hline Deferribacteres & - & $5 \cdot 4$ & $7 \cdot 2$ \\
\hline Deferribacteriaceae & - & $5 \cdot 4$ & $7 \cdot 2$ \\
\hline
\end{tabular}

SD, standard chow diet; HFD, high-fat diet; WD, Western diet.

* 164 16S rRNA gene sequences.

$\dagger 168$ 16S rRNA gene sequences.

$\ddagger 173$ 16S rRNA gene sequences.

whether and to which extent this influence is modulated by diet is largely unknown. We therefore investigated the influence of various diets on the development of obesity depending on the intestinal microbiota. Our main findings are (1) that the absence of gut microbiota does not provide a general protection from the development of diet-induced obesity in mice; (2) that intestinal production of Fiaf/Angptl4 does not play a crucial role as a mediator of gut microbiota-induced effects on fat storage.

\section{Germ-free mice are not generally protected against diet-induced obesity}

Backhed et al. ${ }^{(4)}$ reported that GF mice fed a WD gained less body fat than $\mathrm{CV}$ mice fed the same diet. This was interpreted to mean that GF mice are protected against obesity in spite of being fed a HFD. Using the same diet, we were able to reproduce these results. However, when we fed mice the semi-synthetic HFD with the same overall proportions of macronutrients but composed of different ingredients, we observed that GF mice showed a significant gain of body weight and fat, which was as high as (Expt 2) or even higher (Expt 1) than that observed in the CV mice. Hence, we conclude that GF mice are not generally protected against obesity induced by high fat feeding. Differences in body fat gain observed between GF and CV mice in response to the different diets were not due to differences in food intake and/or diet digestibility. The higher weight gain of GF mice on the HFD was rather due to their lower energy expenditure. On this diet, we observed an $8.3 \%$ lower TEE of GF mice when compared with $\mathrm{CV}$ mice for a $23 \mathrm{~h}$ observation period. 
Table 6. Mean faecal SCFA concentrations ( $\mu \mathrm{mol} / \mathrm{g}$ wet faeces) of conventional mice $(n 5)$ of Expt 3 in response to different diets (standard chow diet (SD), high-fat diet (HFD) and Western diet (WD)) after 3 weeks of diet consumption

(Mean values with their standard errors)

\begin{tabular}{|c|c|c|c|c|c|c|c|c|c|c|}
\hline \multirow[b]{2}{*}{ Diet } & \multicolumn{2}{|c|}{ Acetate } & \multicolumn{2}{|c|}{ Propionate } & \multicolumn{2}{|c|}{ Butyrate } & \multicolumn{2}{|c|}{ Isovalerate } & \multicolumn{2}{|c|}{ Valerate } \\
\hline & Mean & SEM & Mean & SEM & Mean & SEM & Mean & SEM & Mean & SEM \\
\hline SD & 28.8 & $9 \cdot 0$ & $5 \cdot 3$ & $1 \cdot 7$ & $7 \cdot 4$ & 4.4 & 0.6 & 0.2 & 0.4 & 0.3 \\
\hline HFD & $9 \cdot 0^{\star \star \star}$ & 1.5 & $0 \cdot 8^{\star \star *}$ & 0.3 & $0 \cdot 6^{\star *}$ & 0.2 & 0.3 & 0.1 & ND & \\
\hline WD & $10 \cdot 9^{\star \star}$ & 3.7 & $1 \cdot 3^{\star \star \star}$ & 0.7 & $1.0^{\star \star}$ & 0.5 & 0.6 & 0.3 & 0.3 & 0.2 \\
\hline
\end{tabular}

ND, not detected.

Mean values were significantly different in comparison to the SD group: ${ }^{\star \star} P<0.01,{ }^{\star \star \star} P<0.001$.

Using shorter measurements $(1-2 \mathrm{~h})$, it was reported previously that GF mice show a lower oxygen consumption than their CV counterparts ${ }^{(22,25)}$. In line with our observations in GF mice on the LFD and HFD, Wostmann et al. ${ }^{(26)}$ showed that the energy expenditure of GF mice greatly depended on the diet used. Unfortunately, we did not measure energy expenditure on the WD, and thus, cannot exclude the possibility that it affected energy expenditure differently compared with the HFD.

High intestinal fasting-induced adipose factor/angiopoietinlike protein 4 gene expression in germ-free mice does not protect from diet-induced obesity

It has been proposed that the intestinal microbiota promotes fat storage of the host by suppressing the intestinal production of Fiaf/Angptl $4^{(4,22)}$. We analysed whether the differences in fat accumulation which we observed in GF mice on the two HFD are mediated by differences in Fiaf/Angptl4 concentrations. We found higher Fiaf/Angptl4 mRNA concentrations in the mucosa of the distal small intestine of GF mice compared with $\mathrm{CV}$ mice, no matter whether they were fed the HFD or the WD. This argues against an involvement of this factor in the differential effects of these diets. Here, we have shown that increased intestinal Fiaf/Angptl4 mRNA expression was not reflected by increased plasma protein concentrations, nor could we detect Fiaf/Angptl4 in intestinal mucosa. These findings suggest that the intestinal mucosa is not a main contributor to circulating Fiaf/Angptl4 concentrations. This also argues against a role of the intestinal Fiaf/ Angptl4 as an inhibitor of lipoprotein lipase in peripheral tissues of GF mice. Besides its role in lipid metabolism, Fiaf/Angptl4 is a key player in angiogenesis, exhibiting proand anti-angiogenic activities ${ }^{(27,28)}$. Since intestinal bacteria modulate the density of the capillary network in the intestine ${ }^{(29)}$, it may be speculated that intestinal Fiaf/Angptl4 is involved in this process. In any case, the high intestinal Fiaf/Angptl4 gene expression in GF mice deserves further investigation.

\section{Alterations in the gut microbial community in response to dietary changes}

The proportion of intestinal bacteria detectable with the four group-specific probes used in our study decreased within 4 weeks after switching the mice from SD to any of the semi-synthetic diets (HFD, LFD and WD), especially in mice receiving the high-fat diets (HFD and WD). This suggests that bacteria not detectable with these probes proliferated in response to the diet switch. This is in accordance with a recent study which reported a reduction in the Cytophaga-Flavobacterium-Bacteroides phylum and in the E. rectale-C. coccoides cluster in response to $\mathrm{HFD}^{(30)}$.

Feeding the mice a HFD led to a dramatic reduction in microbial diversity and simultaneously to an increase in one subgroup of the Firmicutes referred to as Mollicutes ${ }^{(23)}$. Our sequencing data revealed a three- and sevenfold higher proportion of Erysipelotrichaceae in mice fed the WD and the HFD, respectively, compared with mice fed the SD (Table 5). Our re-analysis of the $16 \mathrm{~S}$ rRNA sequences provided by Turnbaugh et al. ${ }^{(23)}$ revealed that the majority of sequences referred to as Mollicutes belong to the Erysipelotrichaceae. The exact role of this bacterial group in host energy metabolism is still obscure, and deserves further research.

\section{Differential effects of different high-fat diets on obesity development in germ-free mice}

By comparing two semi-synthetic diets, HFD and WD, we demonstrated that mice respond differently to the two diets despite their almost identical overall macronutrient ratio. WD and HFD differ in the types and sources of fats and carbohydrates. For example, the WD contains considerably more sucrose than the HFD (Table 1). The difference in the sucrose content of HFD and WD could be of importance. Gazzinelli et al. ${ }^{(31)}$ observed that $\mathrm{CV}$ mice fed high-sucrose diets were heavier and had a higher carcass fat content than their GF counterparts, suggesting that the sucrose content of the diet had a greater lipogenic effect on $\mathrm{CV}$ mice than on GF mice. They proposed that reducing the activities of the ratecontrolling enzymes of the hexose monophosphate shunt leads to a decreased production of NADPH, which in turn diminishes the capacity of the liver to de novo synthesise fatty acids from carbohydrates. We like others ${ }^{(4)}$ also observed differences in parameters of carbohydrate metabolism, such as a reduced liver glycogen content in GF mice (Table 4). Interestingly, liver TAG levels were elevated only in the livers of CV mice fed the WD. This possibly reflects an improved capability of $\mathrm{CV}$ mice to synthesise TAG from the ingested sucrose. On the other hand, the vegetable shortening used in the WD contains approximately $31 \%$ of trans-fatty acids, 
whereas our HFD does not contain any trans-fatty acids. The consumption of trans-fatty acids has been shown to correlate with insulin resistance and obesity ${ }^{(32)}$. Recently, it has also been shown that a LFD enriched in trans-fatty acids stimulates intrahepatic lipid accumulation in rats ${ }^{(33)}$, which fits with the elevated liver TAG levels we observed in CV mice fed the WD. We are not aware of any studies examining the effects of trans-fatty acids in GF mice. Therefore, it remains to be established which of these differences in diet composition are responsible for the different effects of the two different HFD on body weight and body fat development in GF and CV mice.

Our study clearly shows that the effect of the HFD cannot be attributed to the crude fat content alone. Hence, specific dietary components may affect metabolic pathways and the gut microbial composition to a much larger extent than previously assumed.

\section{Acknowledgements}

The present study was supported by the Deutsches Institut für Ernährungsforschung. The authors thank Ines Grüner and Ute Lehmann for excellent technical assistance. S. K. is a member of EU COST action Mitofood (FA0602). M. B., G. L. and S. K. designed the research; C. K. F., M. M. A. E.-B. and N. H. conducted the research; C. K. F., M. B. and N. H. wrote the paper. M. B. and S. K. had primary responsibility for the final content. All authors read and approved the final manuscript. The authors have no conflicts of interest to disclose.

\section{References}

1. Turnbaugh PJ, Ley RE, Mahowald MA, et al. (2006) An obesity-associated gut microbiome with increased capacity for energy harvest. Nature 444, 1027-1031.

2. Ley RE, Turnbaugh PJ, Klein S, et al. (2006) Microbial ecology: human gut microbes associated with obesity. Nature 444, 1022-1023.

3. Ley RE, Backhed F, Turnbaugh P, et al. (2005) Obesity alters gut microbial ecology. Proc Natl Acad Sci USA 102, 11070-11075.

4. Backhed F, Manchester JK, Semenkovich CF, et al. (2007) Mechanisms underlying the resistance to diet-induced obesity in germ-free mice. Proc Natl Acad Sci USA 104, 979-984.

5. Klaus S (2005) Increasing the protein:carbohydrate ratio in a high-fat diet delays the development of adiposity and improves glucose homeostasis in mice. J Nutr 135, 1854-1858.

6. Daenzer M, Ortmann S, Klaus S, et al. (2002) Prenatal high protein exposure decreases energy expenditure and increases adiposity in young rats. $J$ Nutr 132, 142-144.

7. Klaus S, Rudolph B, Dohrmann C, et al. (2005) Expression of uncoupling protein 1 in skeletal muscle decreases muscle energy efficiency and affects thermoregulation and substrate oxidation. Physiol Genomics 21, 193-200.

8. Ortmann S, Kampe J, Gossel M, et al. (2004) The novel antiobesic HMR1426 reduces food intake without affecting energy expenditure in rats. Obes Res 12, 1290-1297.

9. Ortmann S, Prinzler J \& Klaus S (2003) Self-selected macronutrient diet affects energy and glucose metabolism in brown fat-ablated mice. Obes Res 11, 1536-1544.
10. Petzke KJ, Friedrich M, Metges CC, et al. (2005) Long-term dietary high protein intake up-regulates tissue specific gene expression of uncoupling proteins 1 and 2 in rats. Eur $J$ Nutr 44, 414-421.

11. Boeuf S, Klingenspor M, Van Hal NL, et al. (2001) Differential gene expression in white and brown preadipocytes. Physiol Genomics 7, 15-25.

12. Weber K, Bolander ME \& Sarkar G (1998) PIG-B: a homemade monophasic cocktail for the extraction of RNA. Mol Biotechnol 9, 73-77.

13. Amann RI, Binder BJ, Olson RJ, et al. (1990) Combination of 16S rRNA-targeted oligonucleotide probes with flow cytometry for analyzing mixed microbial populations. Appl Environ Microbiol 56, 1919-1925.

14. Wallner G, Amann R \& Beisker W (1993) Optimizing fluorescent in situ hybridization with rRNA-targeted oligonucleotide probes for flow cytometric identification of microorganisms. Cytometry 14, 136-143.

15. Manz W, Amann R, Ludwig W, et al. (1996) Application of a suite of 16S rRNA-specific oligonucleotide probes designed to investigate bacteria of the phylum cytophaga-flavobacter-bacteroides in the natural environment. Microbiology 142, Pt 5, 1097-1106.

16. Franks AH, Harmsen HJ, Raangs GC, et al. (1998) Variations of bacterial populations in human feces measured by fluorescent in situ hybridization with group-specific $16 \mathrm{~S}$ rRNA-targeted oligonucleotide probes. Appl Environ Microbiol 64, 3336-3345.

17. Harmsen HJM, Elfferich P, Schut F, et al. (1999) A 16S rRNAtargeted probe for detection of lactobacilli and enterococci in fecal samples by fluorescent in situ hybridization. Microb Ecol Health Dis 11, 3-12.

18. Lay C, Sutren M, Rochet V, et al. (2005) Design and validation of 16S rRNA probes to enumerate members of the Clostridium leptum subgroup in human faecal microbiota. Environ Microbiol 7, 933-946.

19. Mueller S, Saunier K, Hanisch C, et al. (2006) Differences in fecal microbiota in different European study populations in relation to age, gender, and country: a cross-sectional study. Appl Environ Microbiol 72, 1027-1033.

20. Frank JA, Reich CI, Sharma S, et al. (2008) Critical evaluation of two primers commonly used for amplification of bacterial 16S rRNA genes. Appl Environ Microbiol 74, 2461-2470.

21. Jequier E, Acheson K \& Schutz Y (1987) Assessment of energy expenditure and fuel utilization in man. Annu Rev Nutr 7, 187-208.

22. Backhed F, Ding H, Wang T, et al. (2004) The gut microbiota as an environmental factor that regulates fat storage. Proc Natl Acad Sci U S A 101, 15718-15723.

23. Turnbaugh PJ, Backhed F, Fulton L, et al. (2008) Diet-induced obesity is linked to marked but reversible alterations in the mouse distal gut microbiome. Cell Host Microbe 3, 213-223.

24. Schwiertz A, Taras D, Schafer K, et al. (2009) Microbiota and SCFA in lean and overweight healthy subjects. Obesity (Silver Spring) 18, 190-195.

25. Bruckner-Kardoss E \& Wostmann BS (1978) Oxygen consumption of germfree and conventional mice. Lab Anim Sci 28, $282-286$.

26. Wostmann BS, Bruckner-Kardoss E \& Pleasants JR (1982) Oxygen consumption and thyroid hormones in germfree mice fed glucose-amino acid liquid diet. $J$ Nutr 112, 552-559.

27. Le Jan S, Amy C, Cazes A, et al. (2003) Angiopoietin-like 4 is a proangiogenic factor produced during ischemia and in conventional renal cell carcinoma. Am J Pathol 162, 1521-1528.

28. Cazes A, Galaup A, Chomel C, et al. (2006) Extracellular matrix-bound angiopoietin-like 4 inhibits endothelial cell adhesion, migration, and sprouting and alters actin cytoskeleton. Circ Res 99, 1207-1215. 
29. Stappenbeck TS, Hooper LV \& Gordon JI (2002) Developmental regulation of intestinal angiogenesis by indigenous microbes via Paneth cells. Proc Natl Acad Sci U S A 99, 15451-15455.

30. Cani PD, Neyrinck AM, Fava F, et al. (2007) Selective increases of bifidobacteria in gut microflora improve high-fatdiet-induced diabetes in mice through a mechanism associated with endotoxaemia. Diabetologia 50, 2374-2383.
31. Gazzinelli RT, Silva ME, Moraes-Santos T, et al. (1991) Effect of high sucrose diets on carcass composition in conventional and germ-free mice. Arch Latinoam Nutr 41, 539-545.

32. Riserus U (2006) Trans fatty acids and insulin resistance. Atheroscler Suppl 7, 37-39.

33. Dorfman SE, Laurent D, Gounarides JS, et al. (2009) Metabolic implications of dietary trans-fatty acids. Obesity 17, 1200-1207. 